Louisiana State University

LSU Digital Commons

Faculty Publications

Department of Biological Sciences

$1-1-1992$

\title{
Linkages Among Preschoolers' Playground Behavior, Outcome Expectations, and Parental Disciplinary Strategies
}

\author{
Craig H. Hart \\ Brigham Young University \\ D. Michele DeWolf \\ Louisiana State University \\ Diane C. Burts \\ Louisiana State University
}

Follow this and additional works at: https://digitalcommons.Isu.edu/biosci_pubs

\section{Recommended Citation}

Hart, C., DeWolf, D., \& Burts, D. (1992). Linkages Among Preschoolers' Playground Behavior, Outcome Expectations, and Parental Disciplinary Strategies. Early Education and Development, 3 (4), 265-283. https://doi.org/10.1207/s15566935eed0304_1

This Article is brought to you for free and open access by the Department of Biological Sciences at LSU Digital Commons. It has been accepted for inclusion in Faculty Publications by an authorized administrator of LSU Digital Commons. For more information, please contact ir@lsu.edu. 


\title{
Linkages Among Preschoolers' Playground Behavior, Outcome Expectations, and Parental Disciplinary Strategies
}

\author{
Craig H. Hart \\ Brigham Young University, craig_hart@byu.edu \\ Michele DeWolf \\ Diane C. Burts
}

Follow this and additional works at: https://scholarsarchive.byu.edu/facpub

Part of the Educational Sociology Commons

\section{BYU ScholarsArchive Citation}

Hart, Craig H.; DeWolf, Michele; and Burts, Diane C., "Linkages Among Preschoolers' Playground Behavior, Outcome Expectations, and Parental Disciplinary Strategies" (1992). Faculty Publications. 2921. https://scholarsarchive.byu.edu/facpub/2921 
Linkages Among Preschoolers'

Playground Behavior, Outcome Expectations, and Parental Disciplinary Strategies

Craig H. Hart

Brigham Young University

and

\section{Michele DeWolf and Diane C. Burts}

Louisiana State University

To explore relationships among parent's self-reported disciplinary strategies, preschoolers' outcome expectations, and playground behavior, 136 mothers of preschool-age children (age range $=39-71$ months) participated in home disciplinary style interviews. Measures of preschoolers' outcome expectations and observations of childrens' prosocial, antisocial/disruptive, and nonsocial/withdrawn playground behavior in preschool settings were also obtained. Results indicated that power-assertive mothers had preschoolers who engaged in more antisocial/disnuptive behavior and who expected successful instrumental outcomes for hostile methods of resolving peer conflict. Preschoolers with such outcome expectations also participated in more antisocial playground behavior. Older preschoolers of inductive mothers engaged in more prosocial behavior and expected prosocial behavior to lead to both instrumental gains and enhanced relations with peers. Preschoolers who were more prosocial envisioned friendlyassertive strategies as leading to instrumental gains and, in the case of iess nonsocial behavior to enhanced relations with peers. Children's outcome expectations were also found to be different for older versus younger preschoolers. Evidence was also obtaind sugesting that matermal discipline and outcom. (a) expectations make separate and independent contributions to children's social and aggressive play behavior

There is an accumulating body of evidence suggesting that naturally occurring patterns of children's playground behavior are related to indices of peer competence (Hart, in press). Likewise, many aspects of parenting skill have also been linked to children's behavior and competence with peers (see Ladd, 1991, in press; Maccoby \& Martin, 1983; Putallaz \& Heflin, 1990, for reviews). For instance, recent findings suggest that maternal inductive discipline may be linked to children's prosocial playground behavior, which, in turn, is related to

This sudy was funded in part by Louisiana Agriculural Experiment Station Project \#2666 and by a Competitive Grant for Graduate Research, College of Agricullure, Louisiana State Lniversity. Portions of this paper were Correspondence concening this paper should be addressed to the first a Chor Deparment of Family Sciences, 1000 SWKT, Brigham Young Liniversity, Provo, UT 84602 greater acceptance by peers (Hart, DeWolf, Wozniak, \& Burts, 1992). Likewise maternal induction has been linked to enhanced communication skills and acceptance by peers (Burleson, Delia, \& Applegate, in press). In contrast, Dishion (1990) reported evidence suggesting that parental power assertion may work through antisocial behavior to promote peer rejection.

Recently, researchers have begun to search for social cognitive mechanisms through which a variety of parenting variables may work to influence child behavior with peers and subsequent peer status (e.g., Dodge, Bates, \& Pettit 1990; Pettit, Dodge, \& Brown, 1988; Pettit, Harrist, Bates, \& Dodge, 1991; Weiss, Dodge, Bates, \& Pettit, in press). Some of these mechanisms include indices of social problem solving, attributional biases, self-efficacy, and attentiveness to relevant social cues (see Hart, DeWolf, \& Burts, in press, for a review).

Another mechanism that may serve-a mediational role between parenting and peer group behavior is that of children's outcome expectations (i.e., consequential thinking skills). As Crick and Ladd (1990) have pointed out, outcome expectations have received increasing attention over the past several decades in the social cognition literature (e.g., Bandura, 1977; Dodge, 1986; Goffman 1969; Mead, 1934; Ross, 1977; Rubin \& Krasnor, 1986; Spivak, Platt, \& Shure, 1976). This construct represents ways that children think about consequences of their actions for themselves and others in peer group situations and is included in several current models of social information processing (Dodge, 1986; Ladd \& Crick, 1989; Rubin \& Krasnor, 1986). With regard to peer group interaction, Rubin and Krasnor (1986) proposed that some children may use less adaptive strategies in the peer group because they do not appropriately consider the consequences of their actions. In support of this hypothesis, Crick and Ladd (1990) found that rejected third and fifth grade children tended to expect aggressive strategies (e.g., commanding a peer) to lead to instrumentally successful outcomes (e.g., getting what they wanted). Similar but marginal findings were obtained by Pettit et al. (1991).

In addition, Perry, Perry, and Rasmussen (1986) found that aggressive children perceived such behavior as resulting in more tangible rewards and less aversive treatment by peers. In a more recent study, Perry, Williard, and Perry (1990) reported that when considering aggression toward victimized classmates, children who tended to expect more tangible rewards from their victims were more likely to expect signs of distress from the victim, and were less likely to expect retaliation than when contemplating aggression toward nonvictimized classmates.

Recent work with school-age children has also been devoted to exploring whether parenting influences work through such outcome expectations to impact on child peer status. Hart, Ladd, and Burleson (1990) found that child expectations of successful outcomes for hostile behavior not only were predictive of rejection by peers but also were predicted by maternal power assertion. Children who expected to get their way by enacting hostile behaviors not only had more power assertive mothers, but also were more rejected by their peers. 
However, such expectations by themselves did not necessarily serve as a mediational mechanism between maternal power assertion and lower levels of child peer status. These findings were interpreted from a cognitive social learning perspective in that consistent child exposure to maternal hostile behavior would provide direct instruction, not only as a means for inter Bandura \& Walters, 1959) but also in envision (e.g. outcomes for such behavior (ieer get (1.e., getting one's way). As Perry et al. (1986) suggested, hostile behavior derived from envisioning such outcomes may become habitual in nature when resolving conflicts with puch outcomes may lack of actual behavioral data limited further examination of this possibility in the Hart, Ladd, and Burleson (1990) investigation. Thus, the major focus of the current study was to examine whether maternal discipline works through outcome expectations to influence child behavior in the peer group.

In an a titempt to explore this issue and to expand upon past research in this area, several aims were pursued in this investigation. Because much of past research has focused only on the effects of power assertive or inductive of past of discipline (see Hart ways that both power assertive and inductive components mas to investigate child outcome components may be related to child outcome expectations. Consistent with results of the Hart, Ladd, and Burleson (1990) investigation with school-age children, we expected that preschoolers of more power assertive mothers would have tendencies to expect antisocial strategies to lead to self-oriented gains (positive instrumental outcome expectations) to the exclusion of relationship considerations. Since inductive discipline highlights positive consequences for prosocial bons. Since inductive consequences for antisocial behavior (see Hart et al., in press), inductive mothers were expected to have preschoolers who envisioned prosocial strategies as leading to positive relationships with others (positive relationship outcome expectations), as well as to more self-oriented (positue relationship outcome expecexpectations). It was also anticipated that maternal induction (as contrasted with power assertion) would be positively linked to prosocial behavior and negatively linked to antisocial/disruptive and nonsocial/withdrawm behaviors (see tively linked to antisocial/disruptive and nonsocial/withdrawn behaviors (see
Hart et al., in press).

The second aim of this study was to extend earlier findings by investigating whether outcome expectations were related not only to disciplinary strategies, but also to actual, rather than antisocial/disruptive and Results of the Hart Ladd and Burleson (1990) playground behavior as well. who pereived (1990) study suggested that children who perceived prosocial strategies as leading to both self-oriented gains and enhanced relations with peers were more preferred as playmated gains and children who expected to get their way pren us playmates. Conversely, preferred. Based on these findings, it was con expectations for pros positive outcom expectations for prosocial behavior would be positively linked to greater enactments of prosocial behavior and to fewer instances of nod to greater enact- behavior. Likewise, it was expected that more positive outcome expectations for antisocial behavior would lead to more antisocial and/or disruptive behavior. Under the assumption that maternal discipline, outcome expectations, and child behavior are interrelated, the final aim was to expectations, and children's outcome expectations served as medim was to determine whether discipline strategies and preschoolers' behavior. Similar approaches for exploring mediational relations used in recent research were employed in this study (see Dodge et al., 1990; Hart et al., 1992; Hart, Ladd, \& Burloyed in this study (see Dodge et al., 1990; Hart et al., 1992; Hart, Ladd, \& Burleson, 1990; Pettit et
al., 1988).

In all analyses, age was included as a factor due to research showing that cooperative acts, person-oriented verbal aggression, and_rough play_increase significantly while nonsocial/withdrawn behavior decreases from the early to late preschool years (see Hart et al., in press; Hartup, 1983; johnson, Christie, \& Yawkey, 1987; Parke \& Slaby, 1983; Ramsey, 1990; Rubin, Fein, \& Vandenberg 1983, for reviews). We anticipated that changes in outcome expectations 1983, for reviews). We anticipated that changes in outcome expectations would likely correspond with these emerging patterns of behavior. For instance, as children became more cognitively mature and more cooperative with peers, it was conceivable that they would be more likely to link cooperative, prosocial behavior with greater expectations of self-oriented gains and enhanced relations with peers.

Child gender was also included as a factor because of past research findings indicating that girls are more likely than boys to seek proximity to others and emphasize interpersonal relations and prosocial behavior with peers. In contrast, boys tend to be more physically active and disruptive in their playground behavior with peers (see Grusec \& Lytton, 1988; Hart et al., in press; Maccoby \& Jacklin, 1985; Parke \& Slaby, 1983, for reviews). Moreover, boys tend to view activities with peers in a more instrumental fashion, while girls focus on relational components of peer group interaction (Borman, Lane, \& Lowe, in press). Thus, for example, it was anticipated that boys, relative to girls, would have more positive instrumental outcome expectations for hostile/disruptive behavior, and that girls, relative to boys, would have outcome expectations for such behavior. Indeed, age and sex difelationship interactions of sex and /or age with behaviorences and noted in of sex and/or age with behavior and parenting styles have been noted in earlier outcome expectations and parenting research (e.g., Crick \& Ladd, 1990; Hart et al., in press; Hart et al., 1992).

Sample

Method

The subjects were 136 preschool-age children (age range $=39-71$ months; median age $=54$ months) attending 1 of 5 childcare programs in a moderate-size southern community. Children ( 67 boys and 69 girls) and their mothers were predominantly white (96\%) and middle to upper middle class as assessed by the Hollingshead Four Factor Index (Hollingshead 1974) class as assessed by (SES) scores ranged from 32 to 66 (possible range of 8-66), with a median of 56 
(see Gottfried, 1985; Hart, Lawrence, Thomasson, \& Wozniak, 1990). Of the 136 children in the overall study, $91 \%$ were from two-parent families. Mothers averaged 16.5 years of formal education (range $=12-23$ years) and were an average of 34 years of age (range $=22-45$ years). Half of the mothers $(50 \%)$ were employed full time, $12 \%$ part time, and $27 \%$ were not employed outside of the home.

Procedures and Instrumentation

Disciplinary strategy interview. The home-disciplinary-style interview and subsequent coding scheme were designed to index maternal tendencies to use primarily inductive or power assertive strategies across several types of situations. This tape-recorded interview was conducted with mothers and was later transcribed for coding purposes. Seven trained female graduate students who were blind to study hypotheses conducted the interviews by following a predefined interview format in which mothers were asked to respond to seven hypothetical situations describing disciplinary contexts. Several of the situations employed were adapted from Applegate, Burke, Burleson, Delia, and Kline (1985), Bearison and Cassel (1975), and Hart et al. (1990). These situations described disciplinary contexts where their child (a) picked flowers in the next door neighbor's flower garden, (b) took a small item from a friend's house without asking for it, (c) refused to go to bed at bedtime on a school night, (d) refused to go to school on a particular day, (e) grabbed a toy away from another child while playing together, $(f)$ hurt the feelings of another child by name-calling, and $(\mathrm{g})$ pushed another child to the ground who had accidently run into him or her. Mothers were asked to mention all possible strategies that they would likely use for each situation.

To avoid item desirability bias, open-ended responses were elicited rather than having mothers select predefined disciplinary responses from a check list 2e Burleson \& Wilson, 1988). Transcripts were later coded using an extensive .1erarchical coding scheme designed to capture varying shades or degrees of the power assertion-induction dichotomy. The coding scheme also allowed for the possibility that mothers may use both power assertion and induction in disciplinary contexts (see Applegate et al., 1985; Hart et al., 1992). ${ }^{1}$ Power-assertive responses (e.g., punishing, coercing, rebuking, providing rules with little or no justification) composed the lower three levels of the continuum. Inductive responses (e.g., explaining consequences and providing rationales, eliciting probable consequences for misbehavior from the child, setting limits and following through with consequences explained in advance) composed the upper three levels.

The hierarchical placement of these responses was guided by both theoretical and empirical considerations (see Applegate et al., 1985; Hart et al., 1992). Scores were created by summing the highest-level strategy elicited for each of the seven situations. These scores ranged from 1 to 6 for each situation (i.e., $1=$

'A detailed interview protocol and coding booklet is available on request. The hierarchical coding scheme was reverse scored in the Hart, Ladd, and Burleson (1990) study. most power assertive; $6=$ most inductive; possible range, $7-42$ ). The rationale for the hierarchical placement and highest-level strategy scores is explained in Hart et al. (1992).

Maternal disciplinary style scores ranged from 7 to 39 , with a mean of 23.27 (median $=25.00)$ and a standard deviation of $6.73(N=136)$. Cronbach's alpha for maternal disciplinary style scores was .74. Two trained coders independently coded maternal responses from the interview transcripts (Cohen's kappa $=.85$ ).

Playground behavioral observations. Children's playground behavior was assessed by a scan sampling procedure (see Ladd \& Price, 1987; Ladd, Price, \& Hart, 1988). All children involved in the study had been together in classrooms for-at-least-3-months-prior-to the-beginning-of-the-investigation.-Five-female observers (separate from the parent interviewers) were trained and recorded children's behavior during 20- to 35-minute free-play periods on the playground. Subjects were observed in a predetermined random order that was changed daily over a 4 to 6 week period. A total of 85 scans (frequency units) per child were coded.

Observers focused on the subject and coded his or her behavior (during each 1-2 second scan) into one of five interactive or five noninteractive categories. The interactive prosocial and antisocial/disruptive categories and abbreviated definitions were as follows: (a) social conversation - face-to-face talk; (b) cooperative play - nondisruptive mutual activity with others; (c) argue hostile talk; (d) rough play - boisterous, quasiagonistic activity; and (e) aggressive - physical harm intended, hostile acts. Nonsocial/ withdrawn behaviors were coded as (a) solitary play - alone and occupied with a nondisruptive task (b) parallel play - play activity near but not with others; (c) unoccupied behavior - alone and off-task; and (d) onlooking behavior - watching others but not interacting. Behaviors oriented toward or interacting with the teacher were coded as "teacher." Agreement between the reliability judge and observers for the observed behaviors (10-15\% overlap of observations on a scan-by-scan basis) was estimated with Cohen's kappa (median kappa $=.86$; range $=.80-95$ ). Measures were created by summing the number of behaviors recorded for each child to create frequency scores in each category.

Outcome expectations interview. Outcome expectations interviews were conducted by the same five female examiners who conducted the behavioral observations. To avoid bias, care was taken to ensure that examiners interviewed children they had not observed. A modified version of the outcome expectations interview used in the Hart, Ladd, and Burleson (1990) investigation was used here. Preschoolers were presented with 2 hypothetical conflict situations and 12 strategies made up of 2 strategy types representing 6 antisocial and 6 prosocial approaches to resolving conflict (e.g., unfriendly-assertive strategy - "What would happen if you said in a mean voice, 'Hey! Give me back my ball!"'; Friendly-assertive strategy - "What would happen if you said in a nice voice, 'Could I please have my ball back?"'). ${ }^{2}$ Children were not presented

\footnotetext{
${ }^{2}$ Detailed procedures are available on request from first author.
} 
with unfriendly-unassertive and friendly-unassertive strategy types reported in Hart, Ladd, and Burleson (1990) due to results of pilot testing indicating that preschoolers have difficulty envisioning outcomes for these types of strategies. Both positive and negative relationship and instrumental outcome possibilities were presented for each strategy (e.g., instrumental outcome - the kid would or would not give you your ball; relationship outcome - the kid would or would not get mad at you). The original measure designed for older children used in the Hart, Ladd, and Burleson (1990) investigation was made up of a 4-point scale for each item by placing 2 identical scale points on each side of the bipolar response_alternatives_(i.e.,--'would_-happen-sometimes,"--or-" would happen most of the time") Because pilot testing revealed that preschoolers had difficuity making the finer distinctions between "sometimes" and "most of the time" for outcome expectations, children were not asked to discriminate be tween these, thus creating a dichotomous scale rather than a four-point scale (e.g., "the kid would or would not give your ball back").

Pictorial representations of the conflict situations and possible outcomes were also used, so that preschoolers did not have to rely entirely on verbal cues to understand the task (e.g.; pictures of the child giving or not giving the ball back). This was particularly helpful to the younger preschoolers. The situations, strategies, and outcome possibilities were presented in a counterbalanced order for 2 versions of the measure.

Separate scores for instrumental and relationship dimensions of the 2 strategy types were created by summing across the categories for the 6 strateges that made up each strategy type. Positive outcome expectations were assigned a 1 , and negative outcome expectations were assigned a 0 . Thus, preschoolers' scores could range from 0 to 6 for each of the instrumental and relationship dimensions for each strategy type. Higher scores were indicative of the child's envisioning more positive instrumental or relationship outcome possibilities across the 6 strategies that made up each of the 2 strategy types. Twenty percent of the sample was retested 4 weeks later to provide an estimate of test-retest reliability. As in the Hart, Ladd, and Burleson (1990) study with school-age children, Cronbach's alphas and test-retest correlations indicated that both the instrumental and relationship dimensions of the unfriendly-assertive strategy type were relatively reliable and stable (alphas $=.78$ and $.71 ; r^{\prime} s=63$ and 56 ) Friendly-assertive strategies exhibited moderate levels of internal consistency and moderate to low levels of test-retest reliability (alphas = .65 and $.68 ; r^{\prime} s=$ .41 and .30 , respectively).

\section{Results}

\section{Overview of Analyses}

Because SES has been related to both child behavior and parental discipline in past research (e.g., Hart, Ladd, \& Burleson, 1990; Hartup 1970, 1983. Hoffman, 1982), correlational analyses were conducted to assess whether the same was true for this sample. Analyses revealed no significant correlations with SES and any of these variables. This was likely due to homogeneity with respect to SES. Likewise, no significant relations were found among family background variables mentioned earlier (e.g., maternal age, education, employment status) and variables of interest for this study. Thus, SES and other family background and variables of interest for this study. Thus, SES
variables were excluded from further analyses.

Regardless of hierarchical placement on the coding scheme, it was deemed that level 4, 5, and 6 strategies that were elicited from mothers would facilitate children's reasoning about the positive consequences of prosocial behavior and the negative consequences of antisocial behavior. In contrast, level 1, and 3 strategies would do little to facilitate such reasoning in children. Therefore, as in Hart et al. (1992), inductive and power assertive groups of maternai discipline were created by performing median splits on maternal and paternal discipline scores, since inductive strategies comprised the upper three levels of the hierarchical coding scheme and power assertive techniques comprised the lower three levels (maternal median $=25$ ). A median split was also performed on child's age (median $=54$ months). Rather than creating measures of prosocial (cooperative play + social conversation) and antisocial behaviors (arguing + aggression) by combining scores as in the Hart et al. (1992) report, interactive behaviors were analyzed separately. This was due to the possibility that outcome expectations might be differentially related to each behavior. For instance, most hypothetical friendly-assertive strategies were verbal in nature. Therefore, it was expected that outcome expectations for this strategy type might be more strongly related to social conversation than to cooperative play.

Because a substantial correlation was found between onlooking and unoccupied behavior, a composite score was created by summing the scores contained in these two catagories and referred to as withdrawn behavior Nonsocial behavior with peers (e.g., solitary play, parallel play, and teacher orientation) were retained as separate scores in subsequent analyses.

All analyses were conducted with the SPSSX MANOVA procedure with unique sums of squares. Wilks's lambda was used to test for multivariate effects. To simplify reporting of results due to the number of effects tested, $F$ values and their probability levels are presented in tables rather than in the text. To achieve parsimony in the presentation of the findings, statistics for all main effects and only significant interactions are reported in the tables unless otherwise specified. All reported means are adjusted for imbalance in the data using standard SPSSX techniques, with standard deviations presented in parentheses next to the means. Findings

Maternal discipline and outcome expectations. Multivariate analysis of variance was used to investigate the contributions of maternal discipline to preschoolers' outcome expectations. ${ }^{3}$ In the MANOVA, the relationship and instrumental outcome expectancy scores for the friendly-assertive and unfriendly-assertive strategy domains were the dependent variables; sex, age, ${ }^{3}$ Similar analyses were also conducted to investigatc the individual and interactive contributions of both maternal
and patemal discipline to children's outcome expectations. Results of analyses involving 106 of the 136 children 
maternal discipline, and all interactions among the three, were the independent variables. Because discipline style was expected to be differentially related to friendly-assertive and unfriendly-assertive strategy types, separate MANOVAs were conducted for these two types of outcome expectation scores.

As seen in Table 1, the main effects of maternal discipline and sex were nonsignificant for friendly-assertive outcome expectations. However, the MANOVA found a significant main effect of age and a significant two-way interaction of maternal discipline with age for friendly-assertive outcome expectations. Univariate analyses revealed a significant main effect of age and a significant two-way interaction of maternal discipline with age for both friendly-assertive-instrumental-and-relationship-outcome-expectations. Thus the significant main effect of age will be interpreted in light of the interaction with maternal discipline (see Johnson \& Wichern, 1988, p. 254). No other interactions were significant.

Table 1

Outcome Expectations and Discipline (Summary of Analyses)

\begin{tabular}{|c|c|c|c|c|c|c|}
\hline \multirow[b]{2}{*}{ Indcpendent variable } & \multicolumn{3}{|c|}{ Univariate $^{\mathrm{a}}$} & \multicolumn{3}{|c|}{ Multivariate } \\
\hline & Dependent variable & $F$ & $p$ & $\mathrm{~F}$ & $d f$ & $p$ \\
\hline \multicolumn{7}{|c|}{ Friendly-assertive outcome expectations } \\
\hline Maternal discipline & $\begin{array}{l}\text { Friendly-assertive (R) } \\
\text { Friendly-assertive (I) }\end{array}$ & $\begin{array}{r}1.01 \\
.03\end{array}$ & $\begin{array}{l}.318 \\
.864\end{array}$ & .80 & $2 / 134$ & .449 \\
\hline Sex & $\begin{array}{l}\text { Friendly-assertive (R) } \\
\text { Friendly-assertive (I) }\end{array}$ & $\begin{array}{l}.09 \\
.90\end{array}$ & $\begin{array}{l}.764 \\
.344\end{array}$ & 1.43 & $2 / 134$ & .243 \\
\hline Age & $\begin{array}{l}\text { Friendly-assertive (R) } \\
\text { Friendly-assertive (I) }\end{array}$ & $\begin{array}{l}7.48 \\
5.14\end{array}$ & $\begin{array}{l}.007 \\
.025\end{array}$ & 3.81 & $2 / 134$ & .025 \\
\hline $\begin{array}{l}\text { Age x maternal } \\
\text { disceipline }\end{array}$ & $\begin{array}{l}\text { Friendly-assertive (R) } \\
\text { Friendly-assertive (I) }\end{array}$ & $\begin{array}{r}13.22 \\
4.46\end{array}$ & $\begin{array}{l}.000 \\
.036\end{array}$ & 6.81 & $2 / 134$ & .002 \\
\hline \multicolumn{7}{|c|}{ Unfriendly-assertive outcome expectations } \\
\hline Maternai discipline & $\begin{array}{l}\text { Unfriendly-assertive (R) } \\
\text { Unfriendly-assertive (I) }\end{array}$ & $\begin{array}{r}.28 \\
4.72\end{array}$ & $\begin{array}{l}.601 \\
.031\end{array}$ & 2.91 & $2 / 134$ & .054 \\
\hline Sex & $\begin{array}{l}\text { Unfriendly-assertive (R) } \\
\text { Unfriendly-assertive (D) }\end{array}$ & $\begin{array}{l}.48 \\
.01\end{array}$ & $\begin{array}{l}.482 \\
.917\end{array}$ & .40 & $2 / 134$ & .670 \\
\hline Age & $\begin{array}{l}\text { Unfriendly-assertive (R) } \\
\text { Unfriendly-assertive (I) }\end{array}$ & $\begin{array}{l}17.69 \\
15.58 \\
\end{array}$ & $\begin{array}{l}.000 \\
.000\end{array}$ & 10.84 & $2 / 134$ & .000 \\
\hline
\end{tabular}

anivariate df for outcome expectation is $1 / 135$

(I) = Instrumental; $(R)=$ Relationship.

An analysis of simple effects indicated that older children of inductive mothers envisioned more positive relational and instrumental outcomes for friendly-assertive strategies than did older children of power assertive mothers $[M=5.00(S D=1.55)$ and $3.92(S D=1.12)$ relational; $5.40(1.18)$ and $4.54(1.82)$ instrumental, respectivelyl. There was no significant effect of maternal discipline for younger children $[M=5.04(1.18)$ and $4.79(1.67)$ relational $5.49(1.35)$ and $5.07(1.50)$ instrumental]. Also, older but not younger preschoolers envisioned

who had both mothers and fathers participate indicated that patemal discipline was unrelated to any of the ourome expectation scores. In response to reviewer suggestions, patemal discipline was dropped from the invescigation simplify the rationale for the study and the presentation of the findings. friendly-assertive strategies as leading to more positive relational and instrumental outcomes $\mid M=5.10(1.36)$ and $4.79(1.56)$ relational; $5.29(1.15)$ and $4.79(1.43)$ instrumental].

As also seen in Table 1, the main effects of maternal discipline and age were significant in the MANOVA for unfriendly-assertive outcome expectations. Univariate analyses revealed significant effects of maternal discipline for instrumental but not relationship outcome expectations for unfriendly-assertive strategies. A significant effect of age but not sex for both instrumental and relationship outcomes for this strategy type was also obtained. No significant interactions were found in any of these analyses

Résults indicated that children of power assertive mothers had a greater tendency to expect to get their way (positive instrumental outcome expectations) when using unfriendly-assertive strategies to resolve peer conflict than did children of inductive mothers $[M=3.90(2.33)$ and $2.99(2.65)]$. Older preschoolers also expected unfriendly-assertive strategies to lead to less positive relationship and instrumental gains than did younger preschoolers $[M=$ $1.72(1.46)$ and 3.13(2.27) relationship; $2.66(1.81)$ and $4.26(2.08)$ instrumental].

Table 2

Behazior and Discipline (Summary of Analyses)

\begin{tabular}{|c|c|c|c|c|c|c|}
\hline \multirow[b]{2}{*}{ Independent variable } & \multicolumn{3}{|c|}{ Univariate $^{\mathbf{a}}$} & \multicolumn{3}{|c|}{ Multivariate } \\
\hline & Dependent variable & $F$ & $p$ & $F$ & df & $p$ \\
\hline \multicolumn{7}{|c|}{ Prosocial behavior } \\
\hline Maternal discipline & $\begin{array}{l}\text { Social conversation } \\
\text { Cooperative play }\end{array}$ & $\begin{array}{l}21.97 \\
15.98\end{array}$ & $\begin{array}{l}.000 \\
.000\end{array}$ & 15.04 & $2 / 135$ & .000 \\
\hline Sex & $\begin{array}{l}\text { Social conversation } \\
\text { Cooperative play }\end{array}$ & $\begin{array}{r}7.08 \\
.06\end{array}$ & $\begin{array}{l}.009 \\
.801\end{array}$ & 3.61 & $2 / 135$ & .030 \\
\hline Age & $\begin{array}{l}\text { Social conversation } \\
\text { Cooperative play }\end{array}$ & $\begin{array}{r}20.78 \\
2.98\end{array}$ & $\begin{array}{l}.000 \\
.087\end{array}$ & 10.47 & $2 / 13 \overline{5}$ & .000 \\
\hline $\begin{array}{l}\text { Maternal discipline } \\
\times \operatorname{sex}\end{array}$ & $\begin{array}{l}\text { Social conversation } \\
\text { Cooperative play }\end{array}$ & $\begin{array}{r}.42 \\
10.16\end{array}$ & $\begin{array}{l}.517 \\
.002\end{array}$ & 5.06 & $2 / 135$ & .008 \\
\hline $\begin{array}{l}\text { Maternal discipline } \\
\times \text { age }\end{array}$ & $\begin{array}{l}\text { Social conversation } \\
\text { Cooperative play }\end{array}$ & $\begin{array}{l}4.76 \\
8.99\end{array}$ & $\begin{array}{l}.031 \\
.003\end{array}$ & 5.52 & $2 / 135$ & .005 \\
\hline \multicolumn{7}{|c|}{ Antisocial/disruptive behavior } \\
\hline Maternal discipline & $\begin{array}{l}\text { Arguing } \\
\text { A ggression } \\
\text { Rough and tumble }\end{array}$ & $\begin{array}{r}10.34 \\
4.23 \\
23.23\end{array}$ & $\begin{array}{l}.002 \\
.042 \\
.000\end{array}$ & 8.57 & $3 / 134$ & .000 \\
\hline Sex & $\begin{array}{l}\text { Arguing } \\
\text { Aggression } \\
\text { Rough and tumbic }\end{array}$ & $\begin{array}{r}.00 \\
3.98 \\
16.06\end{array}$ & $\begin{array}{l}.997 \\
.048 \\
.000\end{array}$ & 8.95 & $3 / 134$ & .000 \\
\hline Age & $\begin{array}{l}\text { Arguing } \\
\text { Aggression } \\
\text { Rough and tumble }\end{array}$ & $\begin{array}{r}.23 \\
.00 \\
3.92 \\
\end{array}$ & $\begin{array}{l}.634 \\
.983 \\
.050 \\
\end{array}$ & 1.83 & $3 / 134$ & .145 \\
\hline
\end{tabular}

Maternal discipline and child behavior. MANOVA was also used to investigate contributions of maternal discipline to child behavior. Prosocial, antisocial/disruptive, and nonsocial/ withdrawn behavior scores were the dependent 
variables in the MANOVA; sex, age, maternal discipline, and all interactions among the three were the independent variables. Because discipline style was expected to be differentially related to prosocial, antisocial/disruptive, and nonsocial/withdrawn behaviors, separate analyses were conducted for the three classes of behavior. As seen in Table 2, the main effects of maternal discipline, sex, and age were significant in the MANOVA for prosocial behaviors, as were the two-way interactions of maternal discipline with sex and of maternal discipline with age. Univariate analyses revealed a significant effect of maternal discipline for both social conversation and cooperative play, and significant effects of sex and age for social conversation but not for cooperative play-In-addition, the-two=way-interaction of maternal-discipline with age was significant for both social conversation and cooperative play, while the interaction of maternal discipline with sex was significant only for cooperative play.

Preschoolers of inductive mothers engaged in more social conversation than did preschoolers of power assertive mothers $[M=10.11(6.05)$ and $6.56(3.65)$. Older preschoolers engaged in more social conversation than did younger preschoolers $[M=10.06(5.92)$ and $6.56(3.84)]$. Females were found to participate in more social conversation than did males $[M=9.33(5.51)$ and 7.29(4.68)].

An analysis of simple effects indicated that daughters of power assertive mothers engaged in substantially less cooperative play than did daughters of inductive mothers $[M=18.55(10.54)$ and $30.59(13.83)]$, but there was no significant effect of maternal discipline for sons [ $M=23.47(8.64)$ and 24.82(6.41)]. In addition, older children of power assertive mothers displayed substantially less cooperative play and less social conversation than did older children of inductive mothers $[M=19.94(10.17)$ and $31.66(9.71)$ for cooperative play; $7.43(4.62)$ and $12.78(6.33)$ for social conversation], but there was no effect of maternal discipline for younger children $[M=22.08(9.62)$ and 23.75(11.23) for cooperative play; 5.60(4.11) and 7.52(4.97) for social conversation]. The means also indicated that daughters of power assertive mothers participated in less cooperative play than did any other group.

The MANOVA for antisocial behaviors found significant main effects for maternal discipline and sex, but not age, and no significant interactions (see Table 2). The univariate results for maternal discipline suggest that children of power assertive mothers tended to engage in more arguing, aggression, and rough-and-tumble play $(\mathrm{R} \& \mathrm{~T})$ than did children of inductive mothers $[M=$ $2.33(3.67)$ and $.82(1.22)$ for arguing; $2.33(3.69)$ and $1.25(2.43)$ for aggression; $7.65(5.70)$ and $3.90(3.93)$ for R \& T]. Univariate analyses also found that boys engaged in significantly more aggression and $R \& T$ than did girls $M s=$ 2.31 (3.47) and 1.27(1.56) for aggression; 7.33(5.54) and 4.22(4.48) for $R \&$ T], with no sex differences for arguing $M=1.57(2.78)$ and 1.56(2.91)].

No significant findings were obtained in analyses of relations between maternal discipline and any of the nonsocial/withdrawn behaviors. Thus, results involving these variables are not presented in the tables.
Outcome expectations and behavior. Separate MANOVAs were conducted exploring main effects and interactions involving age, sex, and outcome expectations on prosocial, antisocial/disruptive, and nonsocial/withdrawn behaviors. ${ }^{4}$ Results for prosocial and antisocial/disruptive behaviors are shown in Table 3. Significant multivariate main effects of instrumental outcome expectations involving friendly-assertive and unfriendly-assertive strategies were found for prosocial and antisocial/disruptive behavior. A significant main effect of sex was also found for antisocial/disruptive behavior. No significant sex and/or age interactions with outcome expectations were obtained in any of the analyses. Furthermore, no significant relations were found between relationship outcome expectations and any of the prosocial and antisocial/disruptive behaviors (not tabled).

Because prosocial and antisocial/disruptive behaviors and outcome expectations were measured on continuous scales, partial regression coefficients Table 3

Interactioe Behavior and Outcome Expectations (Summary of Analyses)

\begin{tabular}{|c|c|c|c|c|c|c|}
\hline \multirow[b]{2}{*}{ Independent variable } & \multicolumn{3}{|c|}{ Univariate $^{\mathrm{a}}$} & \multicolumn{3}{|c|}{ Multivariate } \\
\hline & Dependent variable & $\underline{F}$ & $p$ & $F$ & $d f$ & $p$ \\
\hline \multicolumn{7}{|c|}{ Prosocial behavior } \\
\hline Friendly-assertive (I) & $\begin{array}{l}\text { Social conversation } \\
\text { Cooperative play }\end{array}$ & $\begin{array}{r}7.23 \\
.26\end{array}$ & $\begin{array}{l}.008 \\
.612\end{array}$ & 3.75 & $2 / 134$ & .026 \\
\hline Sex & $\begin{array}{l}\text { Social conversation } \\
\text { Cooperative play }\end{array}$ & $\begin{array}{r}.21 \\
1.18\end{array}$ & $\begin{array}{l}.651 \\
.280\end{array}$ & 1.03 & $2 / 134$ & .360 \\
\hline Age & $\begin{array}{l}\text { Social conversation } \\
\text { Cooperative play }\end{array}$ & $\begin{array}{l}.53 \\
.02\end{array}$ & $\begin{array}{l}.468 \\
.901\end{array}$ & .28 & $1 / 134$ & .758 \\
\hline \multicolumn{7}{|c|}{ Antisocial/disruptive behavior } \\
\hline Unfriendly-assertive (I) & $\begin{array}{l}\text { Arguing } \\
\text { Aggression } \\
\text { Rough and tumble }\end{array}$ & $\begin{array}{r}7.10 \\
4.59 \\
.91\end{array}$ & $\begin{array}{l}.009 \\
.034 \\
.342\end{array}$ & 2.89 & $3 / 133$ & .053 \\
\hline Sex & $\begin{array}{l}\text { Arguing } \\
\text { Aggression } \\
\text { Rough and tumble }\end{array}$ & $\begin{array}{r}.46 \\
5.10 \\
14.32\end{array}$ & $\begin{array}{l}.498 \\
.026 \\
.000\end{array}$ & $\dot{6} .87$ & $3 / 133$ & .000 \\
\hline Age & $\begin{array}{l}\text { Arguing } \\
\text { Aggression } \\
\text { Rough and tumble } \\
\end{array}$ & $\begin{array}{r}.02 \\
.00 \\
3.22 \\
\end{array}$ & $\begin{array}{l}.892 \\
.958 \\
.075 \\
\end{array}$ & 1.54 & $3 / 133$ & .206 \\
\hline
\end{tabular}

Univariate $d$ for behavior $=1 / 135$.

(I) = Instrumental.

were estimated to interpret significant univariate findings shown in Table 3 involving instrumental outcome expectations for friendly and unfriendly-assertive strategies and each behavior (i.e., social conversation, arguing, and

${ }^{4} \mathrm{It}$ is a widely accepted statistical practice to include both categorical and continuous variables in the same "It is a widely accepted statistical practice to include both categorical and continuous variables in the same
"general linear model." In SAS, this is done in PROC GLM; in SPSSX, this is done in MANOVA. In such a framework, partial regression coefficients can be generated for continous, variables, and mean differences can be continuous prediciors and dummy variables. The advantage of the ANOVA using a regression analysis with both interactions) among the catcogrical variables can be evaluated more readily than in the regression framewrork. The magnitude of each relationship has no comparaive meaning with other relationships due to the fact thathe dependent variables differed in both mean and variance. 
aggression). ${ }^{4}$ Resuits indicated that preschoolers who expected to get their way by using friendly-assertive means engaged in more social conversation $(b=.863$, $p<.001)$. Children who had similar expectations for unfriendly-assertive egies tended to be more argumentative and aggressive $(b=.267, p<.01$ for arguing; $b=.238, p<.05$ for aggression). As seen in prior analyses, males were also found to engage in more aggression and rough play than females (see prior section). No significant relationships were found between outcome expectations and cooperative play or rough play.

Table 4

Nonsocial/Withdrawn Behavior and Outcome Expectations (Summary of Analyses)

\begin{tabular}{|c|c|c|c|c|c|c|}
\hline \multirow[b]{2}{*}{ Independent variable } & \multicolumn{3}{|c|}{ Univariate } & \multicolumn{3}{|c|}{-Multivariate } \\
\hline & Dependent variable & $F$ & $p$ & $F$ & $d f$ & $p$ \\
\hline Friendly-assertive (I) & $\begin{array}{l}\text { Solitary play } \\
\text { Parallel play } \\
\text { Withdrawn } \\
\text { Teacher }\end{array}$ & $\begin{array}{r}.32 \\
4.16 \\
.01 \\
8.16\end{array}$ & $\begin{array}{l}.572 \\
.043 \\
.932 \\
.005\end{array}$ & 3.01 & $4 / 132$ & .021 \\
\hline Sex & $\begin{array}{l}\text { Solitary play } \\
\text { Parallel play } \\
\text { Withdrawn } \\
\text { Teacher }\end{array}$ & $\begin{array}{r}1.43 \\
.89 \\
.20 \\
3.99\end{array}$ & $\begin{array}{l}.234 \\
.346 \\
.654 \\
.048\end{array}$ & 1.87 & $4 / 132$ & .120 \\
\hline Age & $\begin{array}{l}\text { Solitary play } \\
\text { Parallel play } \\
\text { Withdrawn } \\
\text { Teacher }\end{array}$ & $\begin{array}{r}1.61 \\
.88 \\
1.61 \\
.12\end{array}$ & $\begin{array}{l}.207 \\
.351 \\
.207 \\
.735\end{array}$ & .68 & $4 / 132$ & .604 \\
\hline Friendly-assertive (R) & $\begin{array}{l}\text { Solitary play } \\
\text { Parallel play } \\
\text { Withdrawn } \\
\text { Teacher }\end{array}$ & $\begin{array}{l}4.89 \\
6.49 \\
1.58 \\
6.46\end{array}$ & $\begin{array}{l}.029 \\
.012 \\
.210 \\
.012\end{array}$ & 3.22 & $4 / 132$ & .015 \\
\hline Sex & $\begin{array}{l}\text { Solitary play } \\
\text { Parallel play } \\
\text { Withdrawn } \\
\text { Teacher }\end{array}$ & $\begin{array}{r}.96 \\
5.50 \\
.00 \\
3.26\end{array}$ & $\begin{array}{l}.329 \\
.020 \\
.947 \\
.073\end{array}$ & 2.70 & $4 / 132$ & .034 \\
\hline Age & $\begin{array}{l}\text { Solitary play } \\
\text { Parallel play } \\
\text { Withdrawn } \\
\text { Teacher } \\
\end{array}$ & $\begin{array}{r}.52 \\
.91 \\
1.80 \\
.17 \\
\end{array}$ & $\begin{array}{l}.470 \\
.343 \\
.182 \\
.685\end{array}$ & .61 & $4 / 132$ & .660 \\
\hline
\end{tabular}

(D) = instrumental $(\mathrm{R})=\mathrm{R}=1 / 135$.

As seen in Table 4, significant multivariate main effects were found for both instrumental and relationship outcome expectations associated assertive strategies for nonsocial/withdrawn behaviors. Significant univariate findings shown in Table 4 were interpreted by calculating partial regression coefficients. Preschoolers who expected to get their way and to enhance relations with others by using friendly-assertive strategies engaged in less parallel play ( $b=-.888, p<.05$, instrumental; $b=-.959, p<.05$, relationship). They also spent less time with the teacher $(b=-.855, p<.05$, instrumental; $b=-.682, p$ $<.05$, relationship). Those who expected positive relations (but not positive instrumental outcomes) to ensue after enacting friendly-assertive strategies were also involved in less solitary play $(b=-.954, p<.05)$. No significant findings were obtained for withdrawn behavior, nor for relations between unfriendlyassertive outcome expectations and nonsocial/withdrawn behaviors (not tabled). Likewise, no significant interactions of outcome expectations with behavior were obtained from analyses reported in this section.

Mediational relationships. Multivariate analysis of covariance was used to investigate whether child outcome expectations mediated relationships between maternal discipline and child behavior. As before discipline served as factors; child behaviors were the dependent variables, and child outcome expectation variables were covariates. In accordance with prior analyses, separate analyses were conducted for prosocial behaviors and antisocial-behaviors. In böth sets of analyses, friendly-assertive outcome expectations served as covariates followed by separate analyses in which unfriendily-assertive outcome expectations were the covariates. Results for prosocial and antisocial/disruptive behavior shown in Table 1 were similar when outcome expectations were controlled in the analysis. Similarly, no significant findings emerged for maternal discipline and nonsocial/withdrawn behaviors when controlling for outcome expectations.

In a final set of ANCOVAs, the relationship between outcome expectations and behavior was investigated when discipline was held constant. Holding discipline constant, the relationship between outcome expectations and each behavior persisted, with results almost identical to those found in Tables 3 and 4 , where discipline was not taken into account. These findings suggest that outcome expectations, by themselves, do not necessarily serve as mediational mechanisms between maternal discipline and child behavior. Rather, outcome expectations and discipline appear to make separate and independent contributions to child behavior.

\section{Discussion}

The present study was designed to explore relationships among maternal self-reported discipline, preschoolers' outcome expectations for friendly- and unfriendly-assertive strategies, and playground behavior. Findings from this investigation with respect to maternal discipline and preschoolers' outcome expectations were supportive of our hypotheses. Similar to findings in research with school-age children (Hart, Ladd, \& Burleson, 1990), preschool-age children who expected to get their way when using unfriendly-assertive means of resolving peer conflict were more likely to have power assertive mothers. As anticipated, children with such outcome expectations also engaged in more argumentative and aggressive playground behavior, which was also linked to power assertive discipline. As expected, preschoolers who were more prosocial and less nonsocial envisioned friendly-assertive strategies as leading to self-oriented gains and, in the case of less nonsocial behavior, to enhanced relation with peers. With regard to the latter, it may well be that children who were more prosocial believed that interactive behavior with peers, rather than nonso$\mathrm{cial} /$ withdrawn behavior, was necessary to foster positive relationships with 
others. Prosocially oriented older preschoolers who had positive relationship and instrumental outcome expectations for friendly-assertive strategies were also more likely to have inductive mothers. Findings from this study also indicated that there were differences in preschoolers' outcome expectations according to age. Older preschoolers, as compared with younger preschoolers, appeared to understand that friendly- rather than unfriendly-assertive strategies can lead to successful relationship and instrumental outcomes. Perhaps this was due to greater cognitive maturity resulting from more experiences with peers and siblings as children progress through their preschool years.

The fact that only positive instrumental and not relationship outcome expectations for friendly-assertive_strategies_were linked_to-prosocial-behavior (i.e., social conversation) suggests that for preschoolers, relationship outcomes in this regard may not be as saiient as getting one's way when actually enacting such strategies. The relationship between positive outcome expectations for friendly-assertive strategies; and social conversation rather than cooperative play was not surprising because the hypothetical friendly-assertive strategies were more verbal in nature.

Why did findings from this investigation suggest that outcome expectations did not necessarily mediate the relationship between maternal discipline and child behavior? These findings parallel earlier findings, which indicated that maternal discipline and outcome expectations make separate and independent contributions to peer status (Hart, Ladd, \& Burleson, 1990). There are several possible explanations. First, from a cognitive social learning perspective, modeled maternal behavior may provide direct instruction as to ways to interact with others that may not necessarily be associated with consequential thinking skills. However, children may also learn that when enacting certain types of behaviors, desired consequences can ensue. Thus, both the pattern of interaction derived from modeled behavior and outcome expectation knowledge derived from practicing certain types of behavior with peers may separately contribute to further enactments of certain behavioral patterns.

Another possibility may be that outcome expectations work in combination with a variety of other social cognitions such as encoding, interpreting social cues, and social problem solving that are suggested in several models of social information processing (e.g., Dodge, 1986; Ladd \& Crick, 1989; Rubin \& Krasnor, 1986). Taken by themselves, outcome expectations may not serve a mediating function. Other possible reasons why mediational linkages are not always found are elaborated by Burleson et al. (in press).

Additional findings suggested that girls, in particular who had power assertive mothers, were less likely to participate in cooperative play. This finding lends some support to our sex-role orientation hypothesis presented in Hart et al. (1992) and suggests that power assertion may dampen girls' more natural inclinations to develop affiliative ties with others (Grusec \& Lytton, 1988). Likewise, findings supported past research suggesting that maternal power assertion is linked to aggressive behavior (see Becker, Peterson, Luria,
Shoemaker, \& Hellmer, 1962; Maccoby \& Martin, 1983; Sears, Maccoby, \& Levin, 1957).

Findings from this investigation also indicated that maternal induction and power assertion have stronger relationships with peer-interactive as opposed to nonsocial/withdrawn behaviors. ${ }^{5}$ In support of past research, boys were also found to engage in less social conversation and in more aggression and R \& T than giris (e.g., Grusec \& Lytton, 1988; Hartup, 1983; Maccoby \& Jacklin, 1985; Parke \& Slaby, 1983; Rubin et al., 1983). Contrary to expectations, no sex differences were found for positive and negative relationship and instrumental outcome expectations. However, in accordance with evidence presented by Borman et al. (in press), suggesting that boys are more instrumentally focused and girls are more relationally focused in peer group interactions, future work should assess whether there are gender diff́erences in overail relational and instrumental outcome expectations. The design of the current measure did not lend itself to such analysis because child scores could not be placed on a single continuum involving both relational and instrumental dimensions.

In addition to limitations pertaining to generalizability for this predominantly white, middle class sample, findings from this investigation should be cautiously regarded until future replicative work is conducted using validating measures of discipline. Although Kochanska, Kuczynski, and Radke-Yarrow (1989) found good correspondence between self-reported and observed childrearing practices, whether or not mothers' responses to hypothetical situations reflect their actual behaviors is still uncertain (e.g., Dishion, 1990; Endsley \& Brody, 1981; Holden \& Edwards, 1989). Future work would also need to overcome inherent limitations in assessing disciplinary practices in contrived analogue and naturalistic observational settings (see Hart et al., in press) Nonetheless, findings from the current study do suggest that the disciplinary strategy assessment used is indexing something important. Similar approaches have been successful in documenting other relationships among maternal discipline, child social cognition, and behavior (e.g., Bearison \& Cassel, 1975 Burleson et al., in press; Hart, Ladd, \& Burleson, 1990).

In summary, results from this study indicated that children glean outcome expectations that impact upon their social and aggressive playground behavior in part, from mothers in disciplinary contexts. These finding garded as only one of many preliminary steps to discovering which social cognitions are most important for mediating aspects of parenting and competence with peers.

\footnotetext{
${ }^{5}$ Howerer
}

Jifferever, the nature of the matemal relationship with nonnsocial/withdrawn behavior appears to be somewhat 
References

Applegate, J. L., Burke, J. A., Burleson, B. R., Delia, J. G., \& Kline, S. L. (1985). Reflectionenhancing parental communication. In I. E. Siegel (Ed.), Parental belief systems (pp.
107-142). Hillsdale, NJ: Erlbaum.

Bandura, A. (1977). Toward a unifying theory of behavior change. Psychological Review,
$84,191-215$.

Bandura, A., \& Walters, R. H. (1959). Adolescent aggression. New York: Ronald.

Bearison, D. J., \& Cassel, T. Z. (1975). Cognitive decentration and social codes: Communicative effectiveness in young children from different family contexts. Developmental Psychology, 11, 29-36.

Becker, W. C., Peterson, D. R., Luria, Z., Shoemaker, D. J., \& Hellmer, L. A. (1962) Relations of factors derived from parent-interview ratings to behavior problems of

nt, $-33,509-535$.

Borman, K. M., Lane, C. H., \& Lowe, D. S. (in press). The role of soccer in a narrative context. in $\mathrm{C} . \mathrm{H}$. Hart (Ed.), Children on playgrounds: Research perspectives and applications. New York: State University of New York Press.

Burleson, B. R., Delia, J. G., \& Applegate, J. L. (in press). Effects of maternal communications and children's social-cognitive and communication skills on children's acceptance by the peer group. Family Relations.

Burleson, B. R., \& Wilson, S. R. (1988). On the continued undesirability of item desirability: A reply to Boster, Hutiter, and Seibold. Human Communication Research, 15 178-191.

Crick, N. R., \& Ladd, G. W. (1990). Children's perceptions of the outcomes of social strategies: Do the ends justify being mean? Developmental Psychology, 26, 612-620.

Dishion, T. J. (1990). The family ecology of boys' peer relations in middle childhood. Child Development, 61, 874-892.

Dodge, K. A. (1986). A social information processing model of social competence in children. In M. Perlmutter (Ed.), Minnesota symposium on child psychology (Vol. 18, pp

Dodge, K. A., Bates, J. E., \& Pettit, G. S. (1990). Mechanisms in the cycle of violence

Endsley, R. C., \& Brody, G. H. (1981). Professional isolation of child and family specialists as revealed in a time series analysis of parent-child relations research methods. Family Relations, 30, 5-15.

Goffman, E. (1969). Strategic interaction. Philadelphia: University of Pennsylvania Press.

Gottfried, A. W. (1985). Measures of socioeconomic status in child development research: Data and recommendations. Merrill-Palmer Quarterly, 31, 85-92.

Grusec, J. E., \& Lytton, H. (1988). Social development. New York: Springer-Verlag.

Hart, C. H. (in press). Toward a further understanding of children's development on playgrounds. In C. H. Hart (Ed.), Children on playgrounds: Research perspectives and

Hart, C. H., DeWolf, D. M., \& Burts, D. C. (in press). Parental disciplinary strategies and preschoolers' play behavior in playground settings. In C. H. Hart (Ed.), Children on playgrounds: Research perspectives and applications. New York: State University of New

Hart, C. H., DeWolf, D. M., Wozniak, P., \& Burts, D. C. (1992). Maternal and paternal disciplinary styles: Relations with preschoolers' playground hehavioral on paternal and peer status. Child Development, 63, 879-892.

Hart, C. H., Ladd, G. W., \& Burleson, B. R. (1990). Children's expectations of the outcomes of social strategies: Relations with sociometric status and maternal disciplinary
styles. Child Development, $61,127-137$.

Hart, C., Lawrence, F., Thomasson, R., \& Wozniak, P. (1990). Measuring socioeconomic status in child development research. Psychological Reports, 67, 457-458.

Carmichael's manual of child psychion and social organization. In P. H. Mussen (Ed.), Carmichael's manual of child psychology (pp. 361-456). New York: Wiley.

Hartup, W. W. (1983). Peer relations. In E. M. Hetherington (Ed.), P. H. Mussen (Series (pp. 103-198). New York: Wilgy: Vol.4. Socialization, personality, and social development

Hoffman, L. W. (1982). Work, family, and the socialization of the child i (Ed.), Review of child development research (Vol. 7, pp. 223-282). Chicago: University of
Chicago Press.

Holden, G. W., \& Ed wards, L. A. (1989). Parental attitudes toward childrearing: Instruments, issues, and implications. Fsychoiogical Bulletin, 106, 29-58.

Hollingshead, A. (1974). Hollingshead's four factor index. Unpublished manuscript. Johnson, J. E., Christie, J. F., \& Yawkey, T. D. (1987). Play and early childhood development
Glenview, IL: Scott, Foresman. Johnson, R. A., \& Wichern, D. W. (1988). Applied multivariate statistical analyses. Engle-

Kochanska, G., Kuczynski, L., \& Radke-Yarrow, M. (1989). Correspondence between mothers' self-reported and observed child-rearing practices. Child Development, 60,
$56-63$.

Ladd, G. W. (1991). Family-peer relations during childhood: Pathways to competence and pathology? Journal of Social and Personal Relationships, 8, 307-314.

Ladd, G. W. (in press). Themes and theories: Perspectives on processes in family-peer relationships. In R. D. Parke \& G. W. Ladd (Eds.), Family-peer relationship: M-pee linkage. Hillsdale, NJ: Erlbaum.

Ladd, G. W., \& Crick, N. R. (1989). Probing the psychological environment Children's cognitions, perceptions, and feelings in the peer culture. In M. Maehr \& C. Ames (Eds.), Advances in motivation and achievement: Motivation enhancing environments (Vol.
6, pp. 1-44). Greenwich, CT: JAI.

Ladd, G. W., \& Price, J. M. (1987). Predicting children's social and school adjustment following the transition from preschool to kinderen's social and school adjustment 1189.

Ladd, G. W., Price, J. M., \& Hart, C. H. (1988). Predicting preschoolers' peer status from their pertacts. Child Development, 59, 986-992.

Maccoby, E. E., \& Jacklin, C. M. (1985). The psychology of sex differences. Stanford, CA:
Stanford University Press. Stanford University Press.

Maccoby, E. E., \& Martin, J. A. (1983). Socialization in the context of the family: Parentchild psychology: Vol. 4. Socialization personality, P. H. Mussen (Series Ed.), Handbook of York: Wiley.
Yol. 4. Socialization, personality, and social development (pp. 1-102). New

Mead, G. (1934). Mind, self, and society. Chicago: University of Chicago Press.

arke, R. D., \& Slaby, R. C. (1983). The development of aggression. In E. M. Hetherington
(Ed.), P. H. Mussen (Series Ed) personality, and social development (Pandbook of child psychology: Vol. 4. Socialization aggression. Child Development $57,700-711$. Cognitive social learning mediators of
a 
Perry, D. G., Williard, J. C., \& Perry, L. C. (1990). Peers' perceptions of the consequences that victimized children provide aggressors. Child Development, 61, 1310-1325.

Pettit, G. S., Dodge, K. A., \& Brown, M. M. (1988). Early family experience, social problem solving patterns, and children's social competence. Child Development, 59 , 107-120.

Pettit, G. S., Harrist, A. W., Bates, J. E., \& Dodge, K. A. (1991). Family interactions, social cognition, and children's subsequent relations. Journal of Social and Personal Relationships, 8, 282-402.

Putallaz, M., \& Heflin, A. H. (1990). Parent-child interaction. In. S. R. Asher \& J. D. Cole (Eds.), Peer rejection in childhood (pp. 189-216). Cambridge: Cambridge University

Ramsey, P. G. (1990, April). Changing levels of social participation in early childhood classrooms. In A. Taylor (Chair), Social competence in the context of schooling. Symposium conducted at the annual meeting of the American Educational Research Association, Boston. .

Ross, L. (1977). The intuitive psychologist and his shortcomings: Distortions in the attribution process. In L. Berkowitz (Ed.), Experimental social psychology (Vol. 10, pp. 173-220). New York: Academic Press.

Rubin, K. H., Fein, G., \& Vandenberg, B. (1983). Play. In E. M. Hetherington (Ed.), P. H. Mussen (Series Ed.), Handbook of child psychology: Vol 4. Socialization, personality, and social development (pp. 103-198). New York: Wiley.

Rubin, K. H., \& Krasnor, L. R. (1986). Social-cognitive and social behavioral perspectives on problem solving. In M. Perlmutter (Ed.), Cognitive perspectives on children's social and behavioral development: Vol. 18. The Minnesota symposia on child psychology (pp. 1-68). Hillsdale, NJ: Erlbaum.

Sears, R. R., Maccoby, E. E., \& Levin, H. (1957). Patterns of child rearing. Evanston, IL: Row, Peterson

Spivak, G., Platt, J. J., \& Shure, M. B. (1976). The problem solving approach to adjustment: $A$ guide to research and intervention. San Francisco, CA: Jossey-Bass.

Weiss, B., Dodge, K. A., Bates, J. E., \& Pettit, G. S. (in press). Some consequences of early harsh discipline: Child aggression and maladaptive social information processing style. Child Development. 